\title{
Effects of inspection figure persistence on a figural aftereffect'
}

\author{
Wencke J. Seltzer and Charles L. Sheridan 2 \\ UNIVERSITY OF MISSOURI AND VA HOSPITAL, KANSAS CITY
}

\begin{abstract}
Abstraet
Four experimental and four control Ss were presented monocularly with a large white circle on a black background (Inspection figure). Then Ss were asked to switch to the opposite eye and make relative size judgments of two smaller circles, equal in size, one of which (the T-figure) was centered on the same point as the I-figure. For FAE control Ss the I-figure was removed during and subsequent to the brief period required to change to the opposite eye, whereas experimental Ss were treated identically except that the I-figure persisted in its former position during testing. Control Ss typically judged the $\mathrm{T}$-figure to be smaller than the comparison figure, thus exhibiting reliable figural aftereffects. Experimental Ss typically judged the $\mathrm{T}$-figure to be larger than the comparison figure, exhibiting a reliable reversal of FAE.
\end{abstract}

\section{Problem}

Deutsch (1964) has proposed that figural aftereffects have their basis in lateral inhibition phenomena in the central nervous system similar to those observed in the Limulus eye by Hartline, Ratliff, \& Miller (1961). During excitation, neural fibers surrounding the active region are inhibited, the degree of inhibition being inversely related to distance from the excited fibers. Upon removal of the source of excitation, the state of hypoexcitability brought on by lateral inhibition is quickly replaced by a condition of hyperexcitability of similar form, but of opposite polarity. The aftereffect is the result of a postulated tendency for distances to be underestimated under conditions of hyperexcitability and overestimated when hypoexcitability prevails.

Deutsch maintains, then, that the process responsible for FAE is the opposite of that which occurs during inspection, and in this respect his theory differs from previous accounts. For example, Köhler \& Wallach (1944) account for FAE by appeal to the persistence of satiation which builds up during inspection. Similarly, Osgood \& Heyer's (1952) adaptation or Eysenck's (1955) reactive inhibition are persisting inspection figure (I-figure) processes. Determination of the relationship between the process prevailing during inspection and the one prevailing during test is thus of considerable relevance in evaluating Deutsch's theory. This relationship was determined in the experiment reported here by measuring the effects of I-figure persistence during the test phase of a figural aftereffect (FAE) experiment. If Deutsch is correct, a reversed FAE should be obtained when the I-figure persists.

Subjects

The Ss were eight undergraduate students who were unacquainted with figural aftereffects.

\section{Apparatus}

The main apparatus was a flat black wooden box 9 in wide, 14 in high and 75 in long with a circular viewing aperture (1 in in diameter) at one end and a spring device and frame to hold the stimulus cards at the other end. Two $100-$ w lights placed in a horizontal position 8 in from the center of the stimulus cards provided illumination through openings on the sides of the box just in front of the cards. The lights were placed at a sharpangle to the surface of the cards to avoid glare, and were not visible to $\mathrm{S}$.

Stimulus cards were made of posterboard, painted flat black, and they were 8 in high and 14 in wide. All of the cards had a solid white $7 \mathrm{~mm}$ square fixation point at their center, the I- and T-figures being centered about a point $75 \mathrm{~cm}$ horizontally from either side of the center of the card.

The I-figure, which was the same for both the control and the experimental condition, was a white ring of $60 \mathrm{~mm}$ outside and $56 \mathrm{~mm}$ inside diameter. For the FAE control condition, the test card contained two white rings, each of $30 \mathrm{~mm}$ outside and $26 \mathrm{~mm}$ inside diameter, placed one on each side of the fixation point such that the $\mathrm{T}$-figure was centered on a point corresponding to the I-circle center, and the comparison circle was placed symmetrically opposite. For the experimental condition, both the I- and T-cards were identical to those for controls, except that the $\mathrm{T}$-figure was surrounded by a ring identical to that used on the I-card, giving an effect equivalent to that of persistence of the I-circle during testing.

\section{Proeedure}

In order to familiarize them with the procedure, all Ss received three preliminary trials with the control card (regular FAE) being used during testing. Then 10 additional trials were given, four Ss continuing to be tested with the FAE control card and four being shifted to the I-figure persistence card. Ss were asked to judge whether the $\mathrm{T}$-figure was larger or smaller than its comparison figure.

The right-left position of the I-figure was varied according to a Gellermann sequence, and the inspection period was fixed at $40 \mathrm{sec}$. All tests were conducted with the eye opposite to the one used for inspection, the shift from I-card to T-card taking place while $S$ shifted to the second eye. At least a 1-min. rest period was given between trials, during which time $\mathrm{S}$ was told to look out a window at distant objects.

\section{Results}

The mean number of "smaller," "same" and "larger" judgments made by the experimental and control group are presented in Table 1. Highly reliable figural aftereffects were obtained from the control group. The mean number of judgments of "smaller" (the expected figural aftereffect response) was 8.25 out of a possible 10. A binomial approximation to the z-distribution with correction for continuity (Siegel, 1956) comparing the number of "smaller" judgments to the number of combined "same" and "larger" judgments showed the FAE to be reliable with $\mathrm{p}<.0001$.

In contrast to the control group, the mean number of "smaller" judgments by the I-figure persistence group was only 2.75. A Mann-Whitney U-test comparing the experimental and control groups on the number of "smaller" judgments yielded a $U$ of $0, p<.03$, showing that the I-figure persistence resulted in a reliable 
Table 1. Mean Numbers of "Smaller," "Same," and "Larger" Judgments Made by the FAE Control and I-Figure Persistence

\begin{tabular}{lcrc} 
& \multicolumn{2}{c}{ Groups } \\
& Smaller & Same & Larger \\
FAE Control & 8.25 & 1.75 & 0 \\
I-Figure Persistence & 2.75 & 0.25 & 7.00
\end{tabular}

diminution in the aftereffect. The control group gave no (reversed aftereffect) judgments of "larger," whereas the mean number of such judgments made by the experimental group was 7.0. The two groups differ in their respective numbers of "larger" judgments with a $\mathrm{p}<.03$ (Mann-Whitney $\mathrm{U}=0$ ).

In order to determine whether the predicted reversal of the figural aftereffect actually occurred, experimental group data were dichotomized into those which did vs. those which did not make the judgment opposite to the usual FAE judgment (i.e. those judging the test figure to be larger than the comparison figure vs. those judging it either smaller than or the same as the comparison figure). A binomial approximation to $\mathrm{z}$ with correction for continuity showed that the reversed aftereffect judgment occurred at a level reliably above chance $(z=2.75 ; p<.02)$.

\section{Diseussion}

The results of this experiment correspond quite closely to the predictions implicit in Deutsch's neurophysiological contrast theory of figural aftereffects (Deutsch, 1964)。Persistence of the I-figure during $\mathrm{T}$-figure presentation results in a very nearly complete reversal of the aftereffect, indicating that the process responsible for the aftereffect is the opposite of whatever process takes place during inspection. The reversed aftereffect appears to be somewhat weaker than the figural aftereffect itself. About $30 \%$ of the judgments made by Ss in the I-figure persistence group were in the same direction as those made by FAE controls (i.e. T-figure "smaller"), whereas there were no judgments of "larger" on the part of FAE controls. It should be noted, however, that size contrast effects resulting from the presence of a large circle during $T$-figure presentation are likely to increase the frequency of "smaller" judgments for I-figure persistence $\mathrm{Ss}$, and this means that any size contrast effects which may have been present were in opposition to the reversed aftereffect.

From the point of view of Deutsch's theory of FAE, the reversed aftereffect should be obtained under conditions of I-figure persistence with very little regard to the duration of the inspection period, and, in fact, reversal should occur when $\mathrm{I}$ - and $\mathrm{T}$-figures are presented concomitantly. There are two reasons for this: first, lateral inhibition builds up relatively rapidly, so that use of anything other than tachistoscopic presentation would mean that the inhibition is likely to be well developed by the time judgments are made, and, second, summation due to inhibition and excitation from the Tfigures themselves can largely be ignored, since it is the modified baseline produced by the I-figure which is of importance. It is interesting to note, in the light of this, that there is a considerable body of experimental evidence comparing illusions (which can be thought of as instances of simultaneous presentation of I- and T-figures) with figural aftereffects, and that reversal effects like those reported here have been quite generally observed. This literature has been excellently summarized by Logan (1962) who went on to make extensive comparisons of visual illusions with figural aftereffects using concentric circles similar to those of the present experiment, and with much the same result. If the illusion produces shrinkage, the aftereffect produces expansion, and vice versa.

Although both the concentric circle illusion data and the I-figure persistence data are in consonance with predictions generated from the neurophysiological contrast theory, it would be dangerous to assume that the data cannot be made to fit the older theories. Rather, the emphasis should be placed on the relative facility with which Deutsch's theory generates these predictions. For example, it is difficult to see how the KöhlerWallach theory, in its present condition, could predict anything for the simultaneous case but recession of the $\mathrm{T}$-figure from the highly satiated area between the Tand I-contours. For the Osgood-Heyer theory, the simultaneous case results in summation of excitation with excitation rather that the summation of adaptation and excitation which is characteristic of successive presentation, but the first shift in contour position should occur when the I- and T-excitation distributions combine to form a single distribution, or, in other words, at contour separations just below the acuity threshold. This is the criticism of the statistical theory which was presented earlier by Deutsch (1956), but it is particularly effective for the simultaneous case.

\section{References}

DEUTSCH, J. A. The statistical theory of figural after-effects and acuity. Brit. J. Psychol., 1956, 47, 208-215.

DEUTSCH, J.A. Neurophysiological contrast phenomena and figural after-effects. Psychol. Rev., 1964, 71, 19-26.

EYSENCK, H. J. Cortical inhibition, figural after-effect and the theory of personality. J. abnorm. soc. Psychol., 1955, 51, 94-106.

HARTLINE, H。K., RATLIFF, F。, \& MILLER, W. H. Inhibitory interaction in the retina and its significance in vision. In E. Florey (Ed.), Nervous inhibition. New York: Pergamon Press, 1961.

KÖLER, W., \& WALLACH, H. Figural after-effects: an investigation of visual processes. Proc. Amer. Phil. Soc., 1944, 88, 269-357.

LOGAN, J.A. An examination of the relationship between visual illusions and figural aftereffects. Ph. D. dissertation, University of Sydney, 1962.

OSGOOD, C. E., \& HEYER, A. W. A new interpretation of figural after-effects. Psychol. Rev., 1952, 59, 98-118.

SIEGEL, S. Nonparametric statistics for behavioral sciences. New York: McGraw-Hill, 1956.

\section{Notes}

1. This research was supported in part by fund 8200 , U.S.V.A. Hospital, Kansas City.

2. Present address: University of Alberta, Calgary, Canada. 